\title{
Circulating miR-22, miR-24 and miR-34a as Novel Predictive Biomarkers to Pemetrexed-Based Chemotherapy in Advanced Non-Small Cell Lung Cancer
}

TINDARA FRANCHINA, ' VALERIA AMODEO, ${ }^{2}$ GIUSEPPE BRONTE, ${ }^{2}$ GIUSEPPINA SAVIO, ${ }^{3}$ GIUSEPPINA R.R. RICCIARDI,' MARIA PICCIOTTO,' ANTONIO RUSSO, ${ }^{2}$ ANTONIO GIORDANO, ${ }^{4,5}$ AND VINCENZO ADAMO $*$

'Unit of Medical Oncology, A.O.O.R. Papardo-Piemonte \& Department of Human Pathology, University of Messina, Messina, Italy

${ }^{2}$ Section of Medical Oncology, Department of Surgical and Oncological Sciences, University of Palermo, Palermo, Italy

${ }^{3}$ Division of Medical Oncology, Department of Oncology, ARNAS Civico - Di Cristina - Benfratelli, Palermo, Italy

${ }^{4}$ Sbarro Institute for Cancer Research and Molecular Medicine and Center of Biotechnology, College of Science and Technology,

Temple University, Philadelphia, Pennsylvania

${ }^{5}$ Department of Medicine, Surgery and Neuroscience, University of Siena, Siena, Italy

Pemetrexed has been widely used in patients with advanced non-small cell lung cancer (NSCLC). The clinical relevance of polymorphisms of folate pathway genes for pemetrexed metabolism have not been fully elucidated yet. The aim of this study was to evaluate the expression levels of circulating miR-22, miR-24, and miR-34a, possibly involved in folate pathway, in NSCLC patients treated with pemetrexed compared with healthy controls and to investigate their impact on patient clinical outcomes. A total of 22 consecutive patients with advanced NSCLC, treated with pemetrexed-based chemotherapy and 27 age and sex matched healthy controls were included in this preliminary analysis. miR-22, miR-24, and miR-34a targets were identified by TargetScan 6.2 algorithm, validating the involvement of these microRNAs in folate pathway. MicroRNAs were isolated from whole blood and extracted with miRNAeasy Mini Kit (Qiagen). miRNA profiling was performed using Real-Time PCR. SPSS 17 was used to data analysis. miR-22, miR-24, and miR-34a were found upregulated $(P<0.05)$ in NSCLC patients versus healthy controls. Higher expression levels were recorded for miR-34a. Nevertheless, significantly higher miR-22 expression was observed in patients developing progressive disease $(P=0.03)$. No significant associations with clinical outcome were recorded for miR-24 and miR-34a. Albeit preliminary, these data support the involvement of miR-22, miR-24, and miR-34a in advanced NSCLC. The correlation between high expression of miR-22 in whole blood and the lack of response in pemetrexed treated NSCLC patients indicates that miR-22 could represent a novel predictive biomarker for pemetrexed-based treatment.

J. Cell. Physiol. 229: 97-99, 2014. (C) 20I3 Wiley Periodicals, Inc.

Despite significant improvements in the treatment of non-small cell lung cancer (NSCLC) over the past several years, the prognosis for patients with advanced disease remains poor.

Chemotherapy resistance is a key contributor to the dismal prognoses for lung cancer patients.

However, important advances have been achieved in the treatment of advanced NSCLC with the introduction of new antiblastic and biological agents.

Lung cancer is driven by genomic alterations, and cancer cells use multiple mechanisms to alter the activity of key genes: mutation, amplification, deletion, intrachromosomal and interchromosomal translocation, and epigenetic mechanisms (MacConaill, 20I2).

The progresses in the field of genomics during the past decade have greatly advanced our understanding of the genomic alterations that contribute to lung cancer, but additional challenges must be addressed before the goal of personalized cancer therapy can become a reality for lung cancer patients.

Pemetrexed, a chemotherapeutic agent already approved in the second-line setting (Hanna et al., 2004), has demonstrated its efficacy also in the first-line treatment combined with cisplatin (Scagliotti et al., 2008) and in the maintenance treatment as single-agent in non-squamous NSCLC (Ciuleanu et al., 2009; Paz-Ares et al., 20I2), paving the way to the so-called histotype-driven approach.

This multitargeted antifolate is unique among the folate antagonists to inhibit at least three different enzymes in the folate pathway: thymidylate synthase (TS), dihydrofolate reductase (DHFR) and glycinamide ribonucleotide formyl transferase (GARFT) (Gridelli et al., 20II).

Contract grant sponsor: Sbarro Health Research Organization. *Correspondence to: Vincenzo Adamo, Unit of Medical Oncology, A.O.O.R. Papardo-Piemonte, Contrada Papardo, 98158 Messina, Italy. E-mail: vadamo@unime.it

Manuscript Received 9 June 2013

Manuscript Accepted I 3 June 2013

Accepted manuscript online in Wiley Online Library (wileyonlinelibrary.com): 24 June 2013.

DOI: $10.1002 /$ jcp.24422 
The clinical relevance of polymorphisms of folate pathway genes for pemetrexed metabolism have not been fully elucidated yet. Several genetic variations associated with folate metabolic pathway and the downstream events have been correlated with clinical outcome in patients treated with pemetrexed (Kim et al., 20l0; Franchina et al., 20l I; Hou et al., 20I2; Tiseo et al., 20I2).

The evolving novel world of microRNA offers an additional regulatory layer affecting drug response. MicroRNAs (miRNAs) are a group of small non-coding, single-stranded RNAs of $\sim 22$ nucleotides, that function as endogenous negative gene regulators by binding to the $3^{\prime}$-untranslated region (UTR) of target mRNAs, repressing mRNA translation or cleaving target mRNA (Lin et al., 20I0). MiRNAs have been implicated in a wide array of fundamental biological processes, such as cell proliferation, differentiation, and apoptosis and thus may function as oncogenes or tumor suppressing genes. Accumulating evidence shows that miRNAs are grossly dysregulated in human cancers, including NSCLC.

Importantly, circulating miRNAs have been characterized as potential blood-based biomarkers for cancer detection. The analysis of circulating miRNA profiles may improve not only the knowledge of miRNA-mediated mechanisms, but may also predict outcome for cancer patients (Gao et al., 20 I I).

However, the role of genetic alterations at miRNA loci in the context of chemotherapy response has not been extensively investigated.

MiRNAs have a key role in the modulation of folatemediated One-Carbon Metabolism (OCM) genes, that comprises a set of reactions involving folate coenzymes, critical for essential processes including DNA methylation, cell proliferation, and the synthesis of nucleic and amino acids (Stone et al., 20I I). Preliminary studies suggest that folate influences miRNA expression (Marsit et al., 2006).

Given these observations, we took a systematic approach to identify which miRNAs could target critical enzymes in folate pathway proteins and consequently influence response to pemetrexed. Recent works have found that dihydrofolate reductase, target enzymes of inhibition by pemetrexed, is regulated at the translational level by miR-24 (Shookhoff and Gallicano, 2010).

Further findings revealed that miR-22 and miR-34a target methylenetetrahydrofolate reductase (MTHFR), key enzyme in folate metabolism (Shookhoff and Gallicano, 2010; Stone et al., 20II).

MTHFR polymorphisms have been associated with clinical outcome in NSCLC patients treated with pemetrexed (Kim et al., 20 I0; Franchina et al., 20 I I; Hou et al., 20I2; Tiseo et al., 20I2).

Therefore, miR-22, mi-R24 and miR-34a might be potential candidate biomarkers to predict pemetrexed response.

The aim of this study was to evaluate the expression levels of circulating miR-22, miR-24, and miR-34a, possibly involved in folate pathway, in NSCLC patients treated with pemetrexed compared with healthy controls and to investigate their impact on patient clinical outcomes.

\section{Materials and Methods}

A total of 22 consecutive patients with advanced NSCLC, before starting treatment with pemetrexed-based chemotherapy and 27 age and sex matched healthy controls were included in this preliminary analysis (Table I). All cases had histological confirmation of their tumor diagnosis.

All subjects were informed and gave written consent to participate in the study to allow their biological samples to be genetically analyzed, according to the Helsinki declaration.

We used the TargetScanS 6.2 algorithm (www.targetscan.org) for genome-wide miRNA target prediction, validating the
TABLE I. Demographic and clinical characteristics of patients

\begin{tabular}{lc}
\hline Characteristics & Patients \\
\hline Median age (range) & $63(46-78$ years $)$ \\
Sex (M/F) & I4/8 \\
Smokers & 16 \\
ECOG PS 0/I/2 & I3/7/2 \\
Stage & IIIB 6 \\
IV 16 \\
Histotype & 19 adenocarcinoma \\
Metastatic sites & 3 large cell carcinoma \\
I & 9 \\
$\geq 2$ & 7 \\
Previous therapeutic lines & \\
0 & 10 \\
I & 9 \\
2 & 3 \\
\hline
\end{tabular}

involvement of miR-22, miR-24, and miR-34a in folate pathway and possibly in pemetrexed metabolism.

For miRNA detection, whole blood samples ( $5 \mathrm{ml}$ per subject) were collected via a direct venous puncture into tubes containing EDTA, leaving the blood at room temperature for $I \mathrm{~h}$. Tubes were then centrifuged at $3,000 \mathrm{~g}$ for $10 \mathrm{~min}$ at room temperature, and the supernatant was aliquoted into Eppendorf tubes and stored at $-80^{\circ} \mathrm{C}$

miRNAs extraction was performed with miRNeasy Mini Kit (QIAGEN, Valencia, CA), designed for the purification of total RNA, including miRNAs and other small molecules of RNA from cultured cells and tissues. After the extraction a quantization was carried out using the spectrophotometer NanoDrop ND- 1000 (CelBio, Euroclone, Pero (Mi), Italy). The miRNAs were retrotranscribed using TaqMan MicroRNA Reverse Transcription Kit (Applied Biosystems, Foster City, CA). Conditions for the reverse transcription reaction were as follows: $16^{\circ} \mathrm{C}$ for $2 \mathrm{~min}, 42^{\circ} \mathrm{C}$ for I min, $50^{\circ} \mathrm{C}$ for I sec for 40 cycles, $85^{\circ} \mathrm{C}$ for 5 min then hold at $4^{\circ} \mathrm{C}$. Obtained cDNA was mixed with TaqMan Gene Expression Master Mix and loaded on a 96 multi-well plate.

Relative levels of gene expression were determined from the fluorescence data generated during PCR using the $A B I$ PRISM7900HT Sequence Detection System. The data analysis was conducted through the SDS software v.2.I. All experiments were repeated at least three times. To normalize quantitative real-time $P C R$ reactions, parallel reactions were run on each sample for RNU6B snRNA. Clinical and outcome data were collected. RECIST criteria were used to evaluate tumor response to pemetrexed.

Statistical analysis was performed using SPSS, version 17.0 (SPSS, Inc., Chicago, USA) for Windows. Intergroup group comparisons were performed using analysis of variance (ANOVA). Differences were considered statistically significant at $P<0.05$.

\section{Results and Discussion}

The expression levels of miR-22, miR-24, and miR-34a were profiled in the serum of 22 NSCLC patient samples, before starting treatment with pemetrexed-based chemotherapy and 27 controls by qRT-PCR assay. The relative expression of miRNAs was described as the difference in threshold cycle number $\left(C_{t}\right)$ between the samples and the controls.

As shown in Figure I, the expression levels of miR-22, miR24 , and miR-34a were found significantly upregulated $(P<0.05)$ in NSCLC patients versus healthy controls. Higher expression levels were recorded for miR-34a.

Moreover, the levels of expression of miRNAs were correlate to the response to pemetrexed-based chemotherapy.

miR-22 upregulation was reported in patients developing progressive disease $(P=0.03)$. No significant associations with clinical outcome were recorded for miR-24 and miR-34a. 


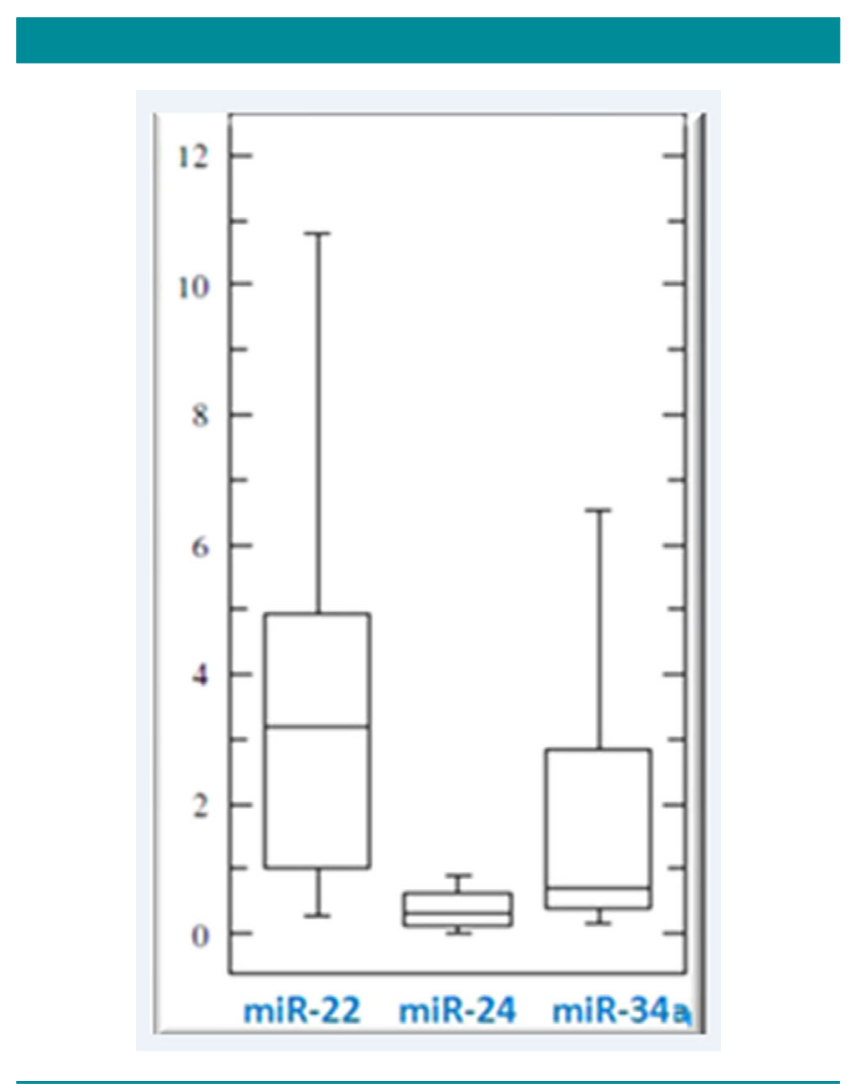

Fig. I. Expression levels of miR-22, miR-24, and miR-34a.

Pemetrexed is extensively used in advanced non-squamous lung cancer treatment, nevertheless few studies have investigated genetic determinants of drug response and resistance to this agent.

The potential role of miRNAs in pharmacogenomics is currently an emerging avenue of investigation.

miRNAs are emerging as intriguing multi-protein target regulators in the context of signaling networks involved in cancer promotion or repression as well as biomarkers for disease progression and response to treatment ( $\mathrm{Di}$ Martino et al., 2013).

In the era of tailored therapies, the noninvasive nature of circulating miRNA collection and their sensitivity and specificity encourage a pursuit of miRNA biomarker research.

Our preliminary data underline the central role of miRNAs as a novel regulatory layer affecting drug metabolism and drug targets, and thus should be taken into account when conducting pharmacogenomic studies.

miR-22 upregulation in non-responder patients should represent a novel predictive biomarker for treatment with pemetrexed, but further investigations are needed to confirm this preliminary observation.

Moreover, the upregulation of miR-22, miR-24, and miR-34a in lung cancer patients could be represent a useful biomarker in the follow up of early stage NSCLC and for innovative approaches to early diagnosis in healthy heavy smokers.

Worldwide lung cancer research has focused on an everincreasing number of molecular elements of carcinogenesis at genetic, epigenetic and protein levels. Proteomics analysis can be a more reliable tool to discover novel cancer biomarkers, particularly for lung cancer, for which, so far, DNA-based biomarkers showed poor sensitivity, specificity, and reproducibility (Indovina et al., 2013).

miRNAs are stably present in sputum of cancer patients and therefore, they represent the main candidates as biomarkers (D'Urso et al., 20I3).

To the best of our knowledge this is the first study reporting a similar correlation and suggesting a possible implication of genetic variations associated with folate metabolic pathway and the downstream events with clinical outcome in NSCLC patients treated with pemetrexed.

Further validations and investigations will be needed to define the role of these miRNAs as useful biomarkers in pemetrexed treated NSCLC patients and evaluate their correlations with genotypes of folate metabolizing enzymes.

\section{Acknowledgments}

Antonio Giordano supported by Sbarro Health Research Organization (www.shro.org).

\section{Literature Cited}

Ciuleanu T, Brodowicz T, Zielinski C, Kim JH, Krzakowski M, Laack E, Wu YL, Bover I, Begbie S, Tzekova V, Cucevic B, Pereira JR, Yang SH, Madhavan J, Sugarman KP, Peterson P, John WJ, Krejcy K, Belani CP. 2009. Maintenance pemetrexed plus best supportive care versus placebo plus best supportive care for non-small-cell lung cancer: $A$ randomised, double-blind, phase 3 study. Lancet 374:1432-1440.

Di Martino MT, Gullà A, Cantafio ME, Lionetti M, Leone E, Amodio N, Guzzi PH, Foresta U, Conforti F, Cannataro M, Neri A, Giordano A, Tagliaferri P, Tassone P. 2013. In vitro and in vivo anti-tumor activity of miR-22I/222 inhibitors in multiple myeloma. Oncotarget $4 \cdot 242-255$.

D'Urso V, Doneddu V, Marchesi I, Collodoro A, Pirina P, Giordano A, Bagella L. 2013. Sputum analysis: Non-invasive early lung cancer detection. J Cell Physiol 228:945-95I. Franchina T, Caristi N, Proto C, Chiofalo G, Toscano G, Ricciardi G, Colonese F, Caccamo D, lentile R, Adamo V. 20I I. Folate pathway implications in advanced Non Small Cell Lung Cancer (NSCLC): Impact of thymidylate synthase (TS) promoter and

methlylenetetrahydrofolate reductase (MTHFR) C677T and A I298C variants expression on patients' outcome and correlation with p53 codon 72 mutations. J Thorac Oncol 6 (suppl 2): S955.

Gao W, Liu L, Lu X, Shu Y. 20I I. Circulating microRNAs: Possible prediction biomarkers for personalized therapy of non-small-cell lung carcinoma. Clin Lung Cancer I2:14-17. Gridelli C, Maione P, Rossi A, Bareschino MA, Schettino C, Sacco PC, Zeppa R. 2011 Pemetrexed in advanced non-small cell lung cancer. Expert Opin Drug Saf $|0: 3| I-3 \mid 7$. Hanna N, Shepherd FA, Fossella FV, Pereira JR, De Marinis F, von Pawel J, Gatzemeier U, Tsao TC, Pless M, Muller T, Lim HL, Desch C, Szondy K, Gervais R. Shaharyar Manegold C, Paul S, Paoletti P, Einhorn L, Bunn PA, Jr., 2004. Randomized phase III trial of pemetrexed versus docetaxel in patients with non-small-cell lung cancer previously treated with chemotherapy. J Clin Oncol 22:1589-1597.

Hou J, Lambers M, den Hamer B, den Bakker MA, Hoogsteden HC, Grosveld F, Hegmans J, Aerts J, Philipsen S. 2012. Expression profiling-based subtyping identifies novel non-small cell lung cancer subgroups and implicates putative resistance to pemetrexed therapy. J Thorac Oncol 7:105-114.

Indovina P, Marcelli E, Pentimalli F, Tanganelli P, Tarro G, Giordano A. 2013. Mass spectrometry-based proteomics: The road to lung cancer biomarker discovery. Mass Spectrom Rev 32:129-142.

Kim J, Yun J, Kong J, Lee S, Kim S, Lee J, Ahn J, Park K, Ahn M. 2010. Correlation of genetic polymorphisms in folate metabolic pathway genes with clinical outcomes in pemetrexedtreated advanced NSCLC patients. I Clin Oncol 28:15s.

Lin PY, Yu SL, Yang PC. 2010. MicroRNA in lung cancer. Br | Cancer 103:1|44-1|48.

MacConaill LE. 2012. Advancing personalized cancer medicine in lung cancer. Arch Pathol Lab Med 136:1210-1216.

Marsit CJ, Eddy K, Kelsey KT. 2006. MicroRNA responses to cellular stress. Cancer Res 66:10843-10848.

Paz-Ares L, de Marinis F, Dediu M, Thomas M, Pujol JL, Bidoli P, Molinier O, Sahoo TP, Laack E, Reck M, Corral J, Melemed S, John W, Chouaki N, Zimmermann AH, Visseren-Grul C, Gridelli C. 2012. Maintenance therapy with pemetrexed plus best supportive care versus placebo plus best supportive care after induction therapy with pemetrexed plus cisplatin for advanced non-squamous non-small-cell lung cancer (PARAMOUNT): A double-blind, for advanced non-squamous non-small-cell lung cancer (PARAM randomised controlled trial. Lancet Oncol 13:247-255.

phase 3, randomised controlled trial. Lancet Oncol 13:247-255.
Scagliotti G, Parikh P, von Pawel J, Biesma B, Vansteenkiste J, Manegold C, Serwatowski P, Gatzemeier U, Digumarti R, Zukin M, Lee JS, Mellemgaard A, Park K, Patil S, Rolski J,
, Goksel T, de Marinis F, Simms L, Sugarman KP, Gandara D. 2008. Phase Ill study comparing cisplatin plus gemcitabine with cisplatin plus pemetrexed in chemotherapy-nalve patients with advanced-stage NSCLC. J Clin Oncol 26:3543-355I.

Shookhoff JM, Gallicano GI. 2010. A new perspective on neural tube defects: Folic acid and microRNA misexpression. Genesis 48:282-294.

Stone N, Pangilinan F, Molloy AM, Shane B, Scott JM, Ueland PM, Mills JL, Kirke PN Sethupathy P, Brody LC. 20II. Bioinformatic and genetic association analysis of microRNA target sites in one-carbon metabolism genes. PLoS ONE 6:e2185I

Tiseo M, Giovannetti E, Tibaldi C, Camerini A, Di Costanzo F, Barbieri F, Burgers JA, Vincent A, Peters G], Smit EF, Ardizzoni A. 2012. Pharmacogenetic study of patients with advanced non-small cell lung cancer (NSCLC) treated with second-line pemetrexed or pemetrexed-carboplatin. Lung Cancer 78:92-99. 